\title{
The Microstructure Changes in IN713LC during the Creep Exposure
}

\author{
Pospíšilová Simona ${ }^{1, a}$, Kianicová Marta ${ }^{2, b}$, Vlasák Tomášs, \\ Hutař Pavel ${ }^{4, d}$, Podrábský Tomáśs,e ${ }^{1, e}$ Hakl Jan ${ }^{3, c}$ \\ ${ }^{1}$ Brno University of Technology, Faculty of Mechanical Engineering \\ Technická 2, 61669 Brno, Czech Republic \\ ${ }^{2}$ Alexander Dubcek University in Trencin, Študentská 2, 91150 Trenčín, Slovak Republic \\ ${ }^{3}$ SVÚM a.s., Laboratory of material properties at high temperatures, \\ Podnikatelská 565, 19011 Praha - Běchovice, Czech Republic \\ ${ }^{4}$ Institute of Physics of Materials, Academy of Sciences of the Czech Republic \\ Žižkova 22, 61662 Brno, Czech Republic \\ apospisilova@fme.vutbr.cz, ${ }^{\mathrm{b}}$ kianicova@tnuni.sk, 'vlasak@svum.cz, \\ 'hutar@ipm.cz, ${ }^{\mathrm{e}}$ podrabsky@fme.vutbr.cz
}

Key words: creep, damage parameter, microstructure changes, rafting, image analysis.

\begin{abstract}
Nickel-based creep resisting alloys (strengthened by $\gamma^{\prime}$ ) are the basic materials for hightemperature constructional parts in aircraft engines and energy units. These parts are exposed to combined effects of mechanical stresses, high temperature and dioxide-corrosion conditions. The microstructure changes of cast polycrystalline Ni-based superalloy IN713LC after creep exposure were studied. Three specimens with three different diameters were used for creep tests. The degradation stage (damage parameter $\pi$ ) was determined for all parts of specimens. Individual parts of specimens were metallographic observed and analyzed by image analysis after rupture. The results were compared with model of stress distribution in the specimen with potential damage in the centre of the specimen.
\end{abstract}

\section{Introduction}

Ni-based superalloys containing hardening ordered $\gamma^{\prime}$ phase have unique high-temperature properties. The precipitates $\mathrm{Ni}_{3}(\mathrm{Al}, \mathrm{Ti})$ ( $\gamma^{\prime}$ phase) are coherent to matrix ( $\gamma$ phase); both embedded in the face-centered cubic. The precipitates having the $\mathrm{L1}_{2}$ structure are stronger than the matrix at high temperatures. The morphology of the $\gamma^{\prime}$ precipitates depends on the thermo-mechanical history of an alloy [1]. Owing to the temperature, stress and time conditions, the creep or an interaction of creep and fatigue may reduce the capability of structures; the directional coarsening of the $\gamma / \gamma^{\prime}$ microstructure may occur, leading to the formation called rafting [2-5]. The direction and shape of the precipitates depend, among other, on the signs of the lattice misfit parameter expressing the relative difference between the lattice parameters $a_{\gamma}$ and $a_{\gamma^{\prime}}$ and the applied creep stress [6]. It is obvious that the rafting will reduce creep life [5].

In the following, we discuss the microstructure changes and the rafting morphology in the microstructure of IN713LC after creep exposure at $800{ }^{\circ} \mathrm{C}$ under various stresses. The lattice parameters were obtained from X-ray diffraction (XRD) and the lattice misfit were negative. According to the [5], rafts form roughly perpendicular to the stress axis for a tensile stress. 


\section{Experimental details}

Material. The cast polycrystalline Ni-based superalloy IN713LC was studied. This material was in the state after casting without heat treatment. The chemical composition is shown in table 1.

Table 1 The chemical composition of IN713LC alloy

\begin{tabular}{|l|c|c|c|c|c|c|c|c|c|}
\hline Chemical element & $\mathrm{C}$ & $\mathrm{Cr}$ & $\mathrm{Ti}$ & $\mathrm{Al}$ & $\mathrm{B}$ & $\mathrm{Zr}$ & $\mathrm{Nb}$ & $\mathrm{Mo}$ & $\mathrm{Ni}$ \\
\hline wt.\% & 0.05 & 12.08 & 0.75 & 5.91 & 0.01 & 0.1 & 2.02 & 4.58 & bal. \\
\hline
\end{tabular}

Creep testing. Creep tests were performed at $800{ }^{\circ} \mathrm{C}$ in air. The specimens with three different diameters were used for these tests. The scheme of testing specimen is shown in Fig. 1. It is obvious that each part of specimen $\left(\mathrm{L}_{1}-\mathrm{L}_{3}\right)$ was loaded by different stresses. The biggest constant load corresponds to stress $360 \mathrm{MPa}$ in diameter $\mathrm{d}_{3}$. The dimensions and stresses are stated in table 2 .

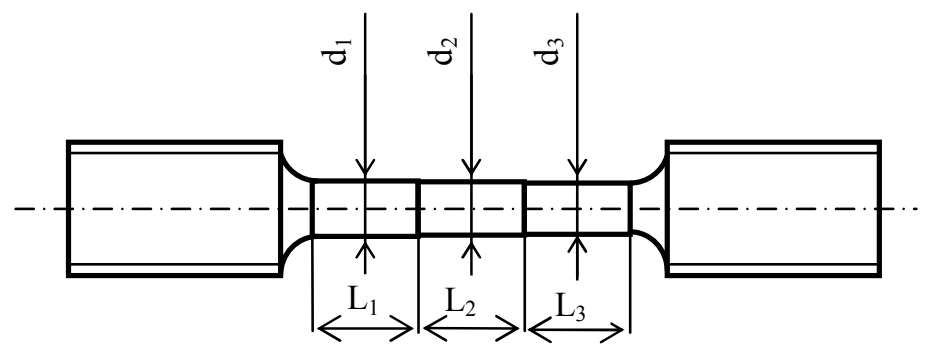

Fig. 1 The scheme of testing specimen.

Table 2 Specimens dimensions

\begin{tabular}{|c|c|c|c|c|c|c|c|}
\hline Specimen & $\begin{array}{c}d_{1} \\
{[\mathrm{~mm}]}\end{array}$ & $\begin{array}{c}d_{2} \\
{[\mathrm{~mm}]}\end{array}$ & $\begin{array}{c}d_{3} \\
{[\mathrm{~mm}]}\end{array}$ & $\begin{array}{c}\text { Stress 1 } \\
{[\mathrm{MPa}]}\end{array}$ & $\begin{array}{c}\text { Stress 2 } \\
{[\mathrm{MPa}]}\end{array}$ & $\begin{array}{c}\text { Stress 3 } \\
{[\mathrm{MPa}]}\end{array}$ & $\begin{array}{c}L_{1}, L_{2}, L_{3} \\
{[\mathrm{~mm}]}\end{array}$ \\
\hline 1 & 4.78 & 4.73 & 4.69 & 346.6 & 353.9 & 360 & 9 \\
\hline 2 & 4.79 & 4.72 & 4.67 & 342.2 & 352.4 & 360 & 9 \\
\hline 3 & 4.79 & 4.69 & 4.59 & 330.6 & 344.8 & 360 & 9 \\
\hline
\end{tabular}

Microstructure analysis. The microstructures were studied by light microscopy (LM) and scanning electron microscopy (SEM) after rupture on the specimens sections longitudinal to the loading axis. The microstructure changes were analyzed by image analysis. The crystallographic orientations were studied by electron backscatter diffraction (EBSD). The observed areas were located directly in the loading axis and the distances between them were approximately $2 \mathrm{~mm}$, see Fig. 2 (white squares). There the studied areas and the distances from the fracture are marked.

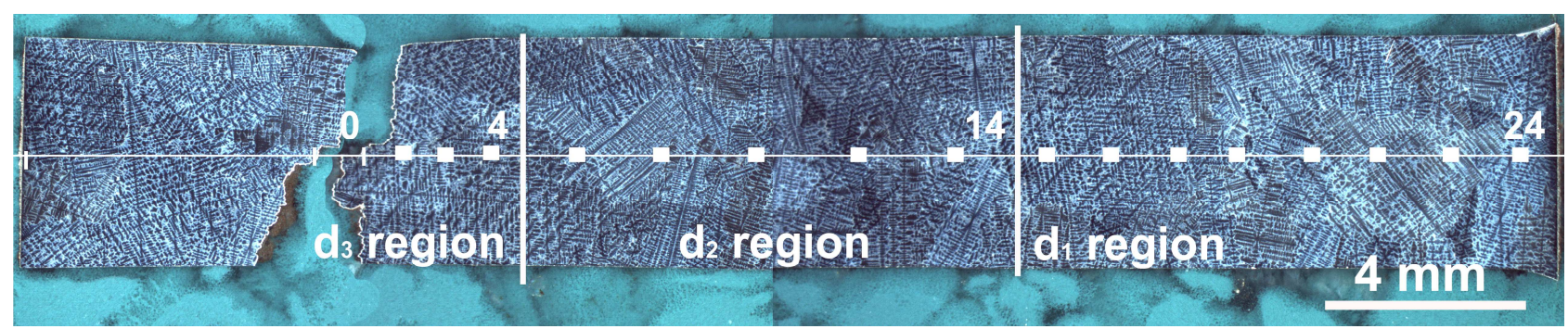

Fig. 2 The macrostructure of specimen 1, section longitudinal to the loading axis; the microstructure were studied by SEM and EBSD in areas marked by white squares, LM 
Finite element modeling. The creep test specimen illustrated in Fig.1. was numerically modeled to find relation between geometry and stress distribution. Due to axisymetry of the specimen geometry and loading, finite element model was built as two-dimensional with axisymertrical boundary conditions. The mesh of the finite elements was nonhomogenously distributed due to stress concentrations in the area where is change of the specimen diameter. Based on numerical results, it was found that the effect of these stress concentrators is small and can be neglected especially in the case of creep loading. Therefore, important question is influence of the creep cracks on the stress distribution in the specimen. For simplicity the model of the creep test specimen (see Fig.1) with potential damage in the centre was modeled. As approximate shape of damaged area was used penny shape crack.

\section{Results}

Creep testing. Mean values of time to rupture were obtained from evaluation of test results on the basis of previous work [7]. Evaluation details are in [7]. For illustration the graphical interpretation of creep strength dependence on Larson-Miller parameter $\mathrm{P}_{\mathrm{LM}}=\mathrm{T} .\left(\log \mathrm{t}_{\mathrm{r}}+\mathrm{C}\right)$, where $T$ is temperature and $t_{r}$ time to rupture, is shown in Fig. 3.

Values of damage parameter $\pi(t)$ (Eq. 1) in a normalized form were also obtained from this testing program [7] in according to [8]. The damage parameters for all parts of testing specimen were estimated (table 3 ).

$$
\pi=\frac{t}{t_{\mathrm{r}}}
$$

where $t$ is creep exposure time and $t_{r}$ is time to fracture.

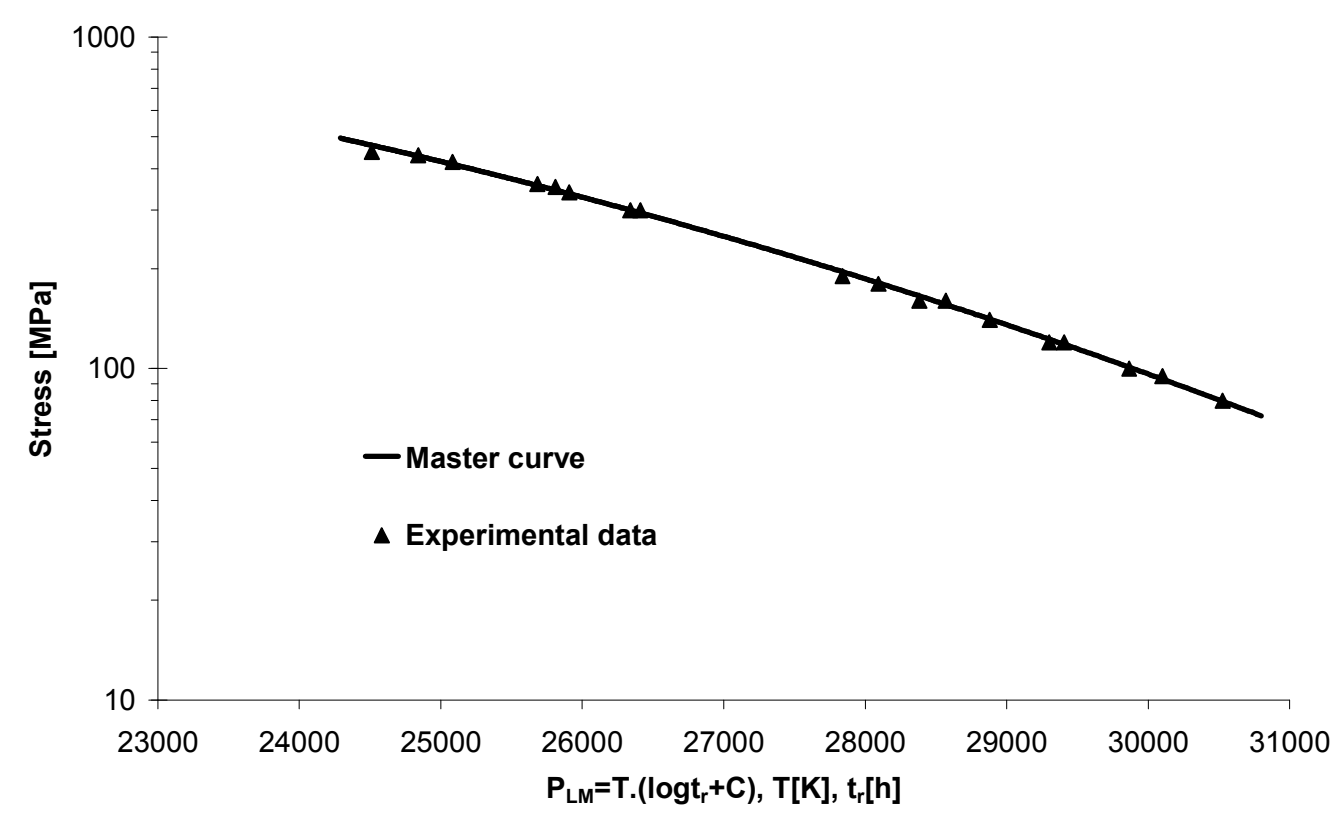

Fig. 3 The dependence of stress to Larson Miller parameter according to [7].

Table 3 Time to rupture and degradation parameter in individual diameters

\begin{tabular}{|c|c|c|c|c|c|c|c|c|c|}
\hline \multirow{2}{*}{ Specimen } & \multirow{2}{*}{$\begin{array}{c}d_{1} \\
{[\mathrm{~mm}]}\end{array}$} & $d_{2}$ & \multirow{2}{*}{$d_{3}$} & \multicolumn{3}{c|}{$\begin{array}{c}\text { Time to rupture } \\
\text { estimation }[\mathrm{h}]\end{array}$} & \multicolumn{3}{|c|}{ Damage parameter $\pi[-]$} \\
\cline { 5 - 10 } & {$[\mathrm{mm}]$} & 1 & 2 & 3 & 1 & 2 & 3 \\
\hline 1 & 4.78 & 4.73 & 4.69 & 1106 & 928 & 802 & 0.73 & 0.86 & 1 \\
\hline 2 & 4.79 & 4.72 & 4.67 & 1232 & 962 & 802 & 0.65 & 0.83 & 1 \\
\hline 3 & 4.79 & 4.69 & 4.59 & 1641 & 1156 & 802 & 0.49 & 0.69 & 1 \\
\hline
\end{tabular}


Microstructure analysis. The cavities were observed in all areas $\left(d_{1}-d_{3}\right)$ of all specimens after creep tests. It would be interesting to determine the relationship between the damage parameter $\pi$ and the distribution, quantity and size of cavities. Unfortunately it was not possible to specify this dependence, because the shrinkage porosity was also found in the microstructure. Some cavities looked like this cast defects. The size of these defects was around $5-100 \mu \mathrm{m}$.

The microstructure changes of $\gamma^{\prime}$ phase were particularly assessed by image analysis from SEM (BSE) images (Fig. 4) from all areas (Fig. 2). The following parameters were chosen; aspect ratio (ratio of length and width of $\gamma^{\prime}$ ) [-], elongation (elongation of $\gamma^{\prime}$ ) [-], area (ratio of sum of $\gamma^{\prime}$ areas to whole area) [-] and mean size (average mean diameter of $\gamma^{\prime}$ ) [ $\left.\mu \mathrm{m}\right]$. The aspect ratio and elongation describe the changes of $\gamma^{\prime}$ morphology, parameters as area and mean size are indicators of $\gamma^{\prime}$ size. Phase $\gamma^{\prime}$ is dark phase on SEM - BSE images from Fig. 4. The crystallographic orientations of each grain coming through specimen axis were obtained from EBSD (OIM). The inverse pole figures (IPF) are shown in Fig. 4.

The changes of the distribution and size of carbides were not observed.
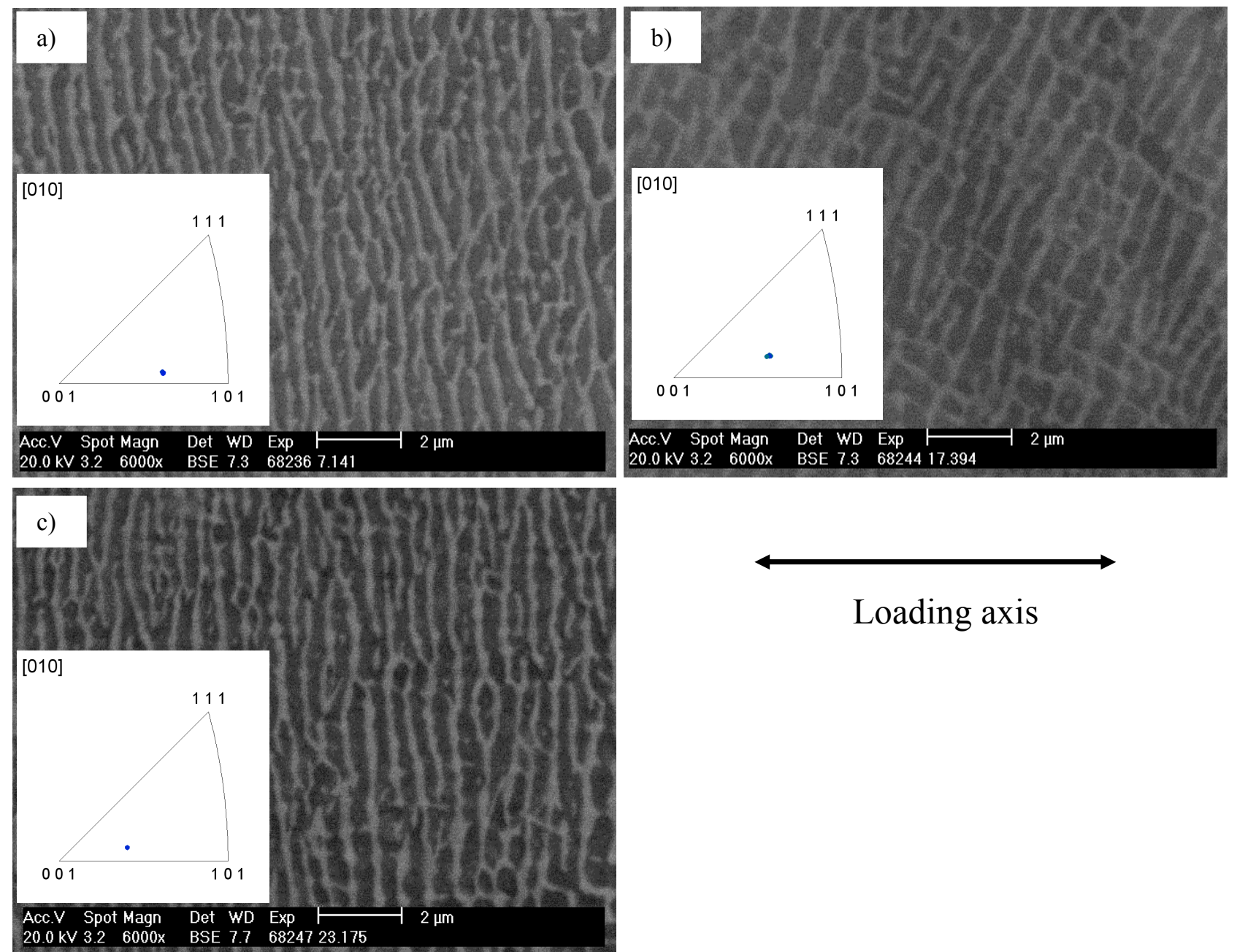

Loading axis

Fig. 4 The microstructure of IN713LC with IPF [010], TD = loading axis, specimen 1, SEM, EBSD; a) from $d_{1}$ region; b) from $d_{2}$ region; c) from $d_{3}$ region.

The results from image analysis were statistically evaluated. The dependence of the structural parameters and the distance from fracture or the stress from $d_{1}-d_{3}$ region are shown in Fig. 5.

The $\gamma^{\prime}$ fraction with stress value and distance from the surface were almost unchanged and respond to $52 \%$ approximately. But the morphology of precipitates $\gamma^{\prime}$ and mean size increase with stress value and with decreasing distance from fracture. 


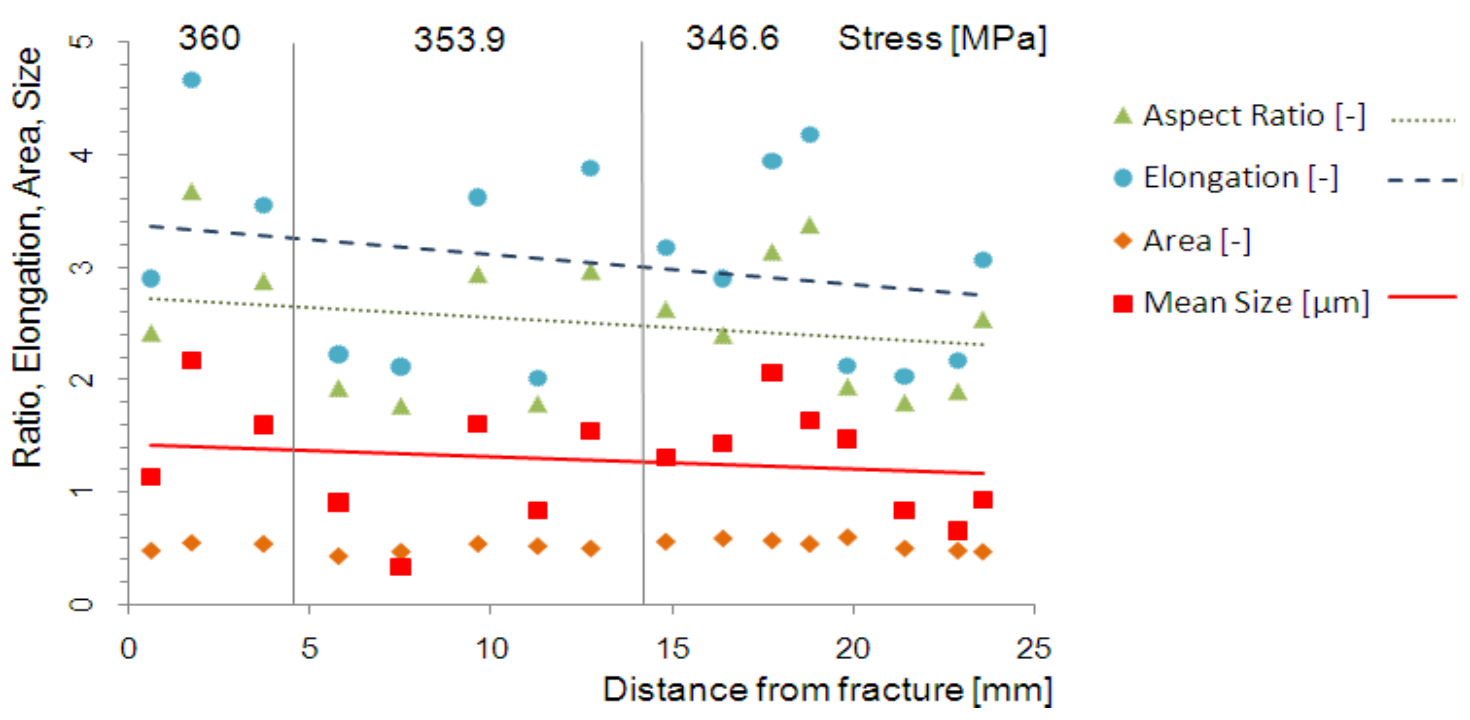

Fig. 5 The dependence of structural parameters and the distance from fracture or the stresses from $d_{1}$ $-d_{3}$ regions in specimen 1 .

Finite element modeling. The results of the finite elements are shown in Fig.6 and 7. It is visible that there is high triaxiality of the stresses in the area close to the creep crack. Size of this region depends on the actual damage zone size and probably is smaller than $2 \mathrm{~mm}$. Then, part of the specimen is influenced by stress redistribution, due to the creep crack existence. The stresses SX and SZ have similar dependence, which is given by axisymetry of the model, see Fig. 6 (center of the creep specimen). There is area of the strong stress decrease in the center of the specimen and strong increase on the free surface, see Fig.7. Cross hatched area near the free surface is area of the stresses which are higher than $400 \mathrm{MPa}$. Shift of the stress scale to smaller values was used due to better visibility of the stress distribution in the center of the specimen, where microstructure observations were done. Redistribution of the stress state in the center of the specimen can lead in the case of high creep loading levels to the nonhomogenous change of the microstructure. However these changes will be important in $d_{3}$ region only.

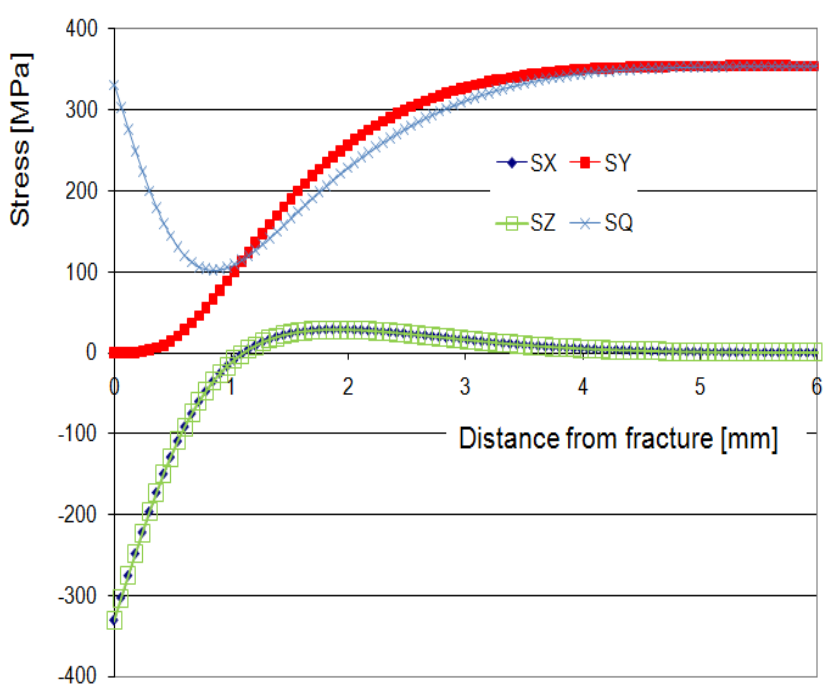

Fig. 6 The stress distribution in the area close to the crack tip (center of the specimen); SQ is von Mises stress; SX, SY, SZ are the stress components; $\mathrm{SY}$ is stress in the loading direction.

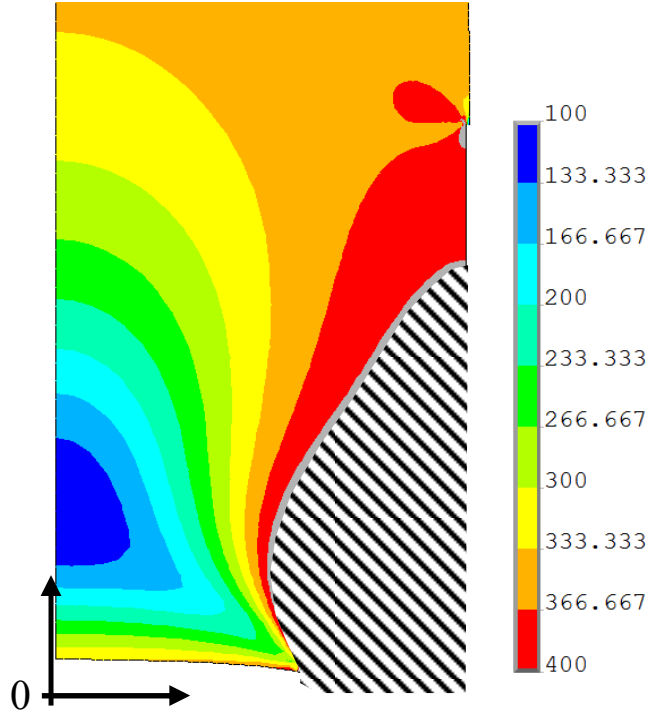

Fig. 7 The stress distribution close to the crack tip, the specimen centre is on the left, shown area is about $4 \mathrm{~mm}$. Crack tip location corresponds to the experimental observations in Fig. 2. 


\section{Summary}

Samples with varying degrees of creep damage were studied by metallographic analysis. Observed structural parameters (aspect ratio, elongation and particle size) showed dependence on the degree of degradation (stress value).

The fraction of precipitates $\gamma^{\prime}$ with stress value and with distance from the surface were almost unchanged, but morphology of precipitates $\gamma^{\prime}$ with stress value and distance varied by comparison with as-cast state. With increasing stress value the elongation and aspect ratio of $\gamma^{\prime}$ particles occurs in a direction nearly perpendicular to the stress. Rafting of structure corresponds to the grain orientation.

The numerical model of the cracked specimen, which describes the redistribution of stress due to larger defect in creep exposure region, was developed. Because, the size of the area, which is affected, is approximately $3-4 \mathrm{~mm}$, and probably $d_{2}$ region slightly influenced, the structure is affected minimally here. Since there are difficult to estimate the location and size of creep cracks, the results of this numerical model are only qualitative and do not give a precise quantitative estimation of this distance.

To further investigation of the model stress distribution in the specimen is therefore necessary to define the shape of the creep crack and creep damage process in the course of time. To verify these findings further experiments are being prepared.

\section{Acknowledgements}

This research was supported by the Czech Science Foundation (project 106/09/P522), Ministry of Education, Youth and Sports (project MEB0810123), Brno University of Technology (project of specific research FSI-S-10-46), Ministry of Industry and Trade (project FR-TI1/099).

\section{References}

[1] N. Ratel, g. Bruno, P. Bastie, T. Mori: Acta Materialia. Vol. 54 (2006), p. 5087-5093.

[2] M. J. Donachie, S. J. Donachie: A technical Guide, Second Edition. ASM International (2002), p. 409

[3] J. Pokluda, M.Kianicová, J. Švejcar, in: Failures 2008, Strand, South Africa, p. 139-159

[4] H. M. Tawancy, L. M. Al-Hadrami: Engineering Failure Analysis. Vol. 16 (2009), no. 1, p.273280.

[5] H. Mughrabi, in: The Johannes Weertman Symposium, 1995, p. 267-278.

[6] J. C. Chang, S.M.Allen: J. Mater. Res. Vol. 6 (1991), p. 1843-1855.

[7] S. Pospíšilová, T. Vlasák, T. Podrábský, J. Hakl, M. Juliš: Materials Science Forum, Vol. 567568 (2008), p. 273-276

[8] R. Pech, J. Koucký, V. Bína: Engineering (SK journal) 29, Vol. 7 (1979), p. 389. 